\title{
Electric Cooking Diary in Bangladesh: Energy Requirement, Cost of Cooking Fuel, Prospects, and Challenges
}

\author{
Avijit Saha ${ }^{1,2, *(\mathbb{D}, \text { Md. Abdur Razzak }}{ }^{2}$ and M. Rezwan Khan ${ }^{1}$ \\ 1 Department of Electrical and Electronic Engineering, United International University, \\ Dhaka 1212, Bangladesh; rezwanm@uiu.ac.bd \\ 2 Department of Electrical and Electronic Engineering, Independent University Bangladesh, \\ Dhaka 1229, Bangladesh; razzak@iub.edu.bd \\ * Correspondence: avijit@eee.uiu.ac.bd
}

Citation: Saha, A.; Razzak, M.A.; Khan, M.R. Electric Cooking Diary in Bangladesh: Energy Requirement, Cost of Cooking Fuel, Prospects, and Challenges. Energies 2021, 14, 6910. https://doi.org/10.3390/en14216910

Academic Editors: Antonio Lecuona and Manolis Souliotis

Received: 7 August 2021

Accepted: 13 October 2021

Published: 21 October 2021

Publisher's Note: MDPI stays neutral with regard to jurisdictional claims in published maps and institutional affiliations.

Copyright: (c) 2021 by the authors. Licensee MDPI, Basel, Switzerland. This article is an open access article distributed under the terms and conditions of the Creative Commons Attribution (CC BY) license (https:// creativecommons.org/licenses/by/ $4.0 /)$.
Abstract: Detrimental effects exerted by biomass-based traditional cookstoves on health, environment, hygiene, and the soaring price of gas makes it imperative to investigate the feasibility of electric cooking as a promising clean cooking fuel in the context of Bangladesh. However, the adoption of electric cooking is unlikely to be welcomed if the monthly cost of electricity consumed by the electric cooking appliances is not comparable to traditional cooking fuels. So far, no study has been reported in this respect. Therefore, this paper is aimed to assess the energy consumption of available electric cooking appliances for cooking typical Bangladeshi dishes. Estimated monthly electricity cost of electric cooking is also reported and then compared to that of traditional cooking fuels. For the study purpose, three respondent families were provided with a rice cooker, hot plate, induction cooker and electric pressure cooker for cooking their daily meals. After four months of use, data related to dish cooked, amount of food, cooking time, and energy consumption were collected which shows that hot plate and rice cooker were the least preferred appliances due to their poor workmanship and limited use respectively. On the contrary, despite the fact that electric pressure cookers cannot perform all types of frying, it was the most preferred appliance owing to its ability to significantly reduce the cooking time and its less energy consumption. Induction cooker was less preferred for the additional requirement of compatible cook pots. The study also reveals that monthly energy requirements for electric cooking varied from $72-87 \mathrm{kWh}$ corresponding to a cooking electricity bill ranging from BDT 504-609 per month (USD 6-7.5) which is less expensive as compared with biomass and LPG based cooking. This paper also highlights the prospects and challenges associated with the adoption of electricity as the primary cooking fuel in Bangladesh.

Keywords: clean cooking; cooking appliance; cooking diary; electric cooking; energy consumption; cost of cooking

\section{Introduction}

Bangladesh is one of the fastest growing economies in the last decade and has made great strides with a whopping increase in per capita GDP from USD 702 in 2009 to USD 1968 in 2020 [1]. Despite an increasing trend in rural to urban migration driven by this economic proliferation, about $63.4 \%$ of the total population still resides in rural areas [2] The power sector has witnessed a monumental growth in the last decade with a generation capacity of 25,171 MW (2021), where more than $90 \%$ of the total population has access to electricity, and the annual per capita electricity consumption has escalated to $510 \mathrm{kWh}$ in 2021 [3]. Owing to this alluring economic growth and elevated access to electricity, a positive trend can be seen in the consumption pattern of numerous electric home appliances ranging from small scale to large scale not only in urban areas but also in peri-urban and rural areas also. Bangladesh is currently in a state where it has over-capacitated power generation infrastructure although the real utilization is much less. According to the annual report from the Bangladesh Power Development Board (BPDB), the utilization factor of the 
overall power sector has dropped from 43\% in 2019 to $40 \%$ in 2020 [4]. This phenomenon introduces a concern that surplus generation capacity can mount up overhead costs.

The market of cooking fuels in Bangladesh, like most other developing countries, is substantially occupied by biomass which includes wood, agricultural crops, animal dung, straw, shrubs, grass, charcoal, etc. Most people use traditional cook stove (TCS) which is basically a clay-made three-stone cook stove. Gas is mainly used by urban consumers where they have access to natural gas (NG) supplied by gas distribution companies. In peri-urban and rural areas, people do not have access to the national gas grid; hence, they must use liquefied petroleum gas (LPG) cylinders. However, only $1.1 \%$ of the total population, out of which, a negligible percentage is from peri-urban and rural areas, uses electricity as the primary cooking fuel [2]. In rural areas, many affluent families can afford to have multiple cook stoves-clay cook stove as primary and gas burner as a secondary option. Electric cooking appliances are the least popular choice and among electrical cooking appliances, the rice cooker is the most used one.

Biomass-based cooking is the most deleterious as far as the environment, human health, safety, and kitchen hygiene are concerned [5-12]. As a matter of fact, these impacts are most severe in rural areas of African, South American, and Asian developing countries [13]. Bangladesh, being a developing country in Asia, is no exception and reports almost 7000 child deaths every year inevitably as a result of chronic lower respiratory infection-related ailments due to their prolonged exposure to biomass smoke and fumes in the kitchen [14]. To alleviate the adverse footprints of biomass-based cooking by TCS, the World Health Organization (WHO) has published a guideline to steer the adoption of clean cooking technologies [15]. Bangladesh is prioritizing improved cook stove (ICS), a biomass-based cook stove with an improved ventilation facility that releases the smoke outside the kitchen through a vent pipe. ICS, compared to TCS, demonstrates improved health benefits, as well as consumes less biomass [16,17]. A myriad of studies reveals that a typical Bangladeshi family spends almost $3-5 \mathrm{~kg}$ of firewood every day for cooking which results in a monthly cost of BDT 600-900 [18-20]. Although the Government of Bangladesh is striving to attain the target that $100 \%$ of the Bangladeshi families will have access to clean and efficient cooking stoves by 2030, as stated in its Country Action Plan [21], ICS could not make a deep penetration in the market triggered by the poor quality of the cook stoves, dismantling of the stoves due to lack of training, and the reluctance of the rural people regarding adopting new technology. Limited biomass options and the challenge of keeping the stove dry during monsoon are also responsible for impeding the success of the ICS project [22-25].

Despite the high cost of NG, LPG, and gas burners compared to biomass fuel and ICS, the share of gas as a cooking fuel is continuing to grow, standing at nearly $25 \%$, while with a decreasing trend, biomass constitutes almost $69 \%$ of the cooking fuel market [7]. Gas is comparatively a cleaner solution; however, the price of natural gas is likely to increase in the near future as the government is not allowing establishing any new gas connection to residential consumers for cooking purposes considering the risk of failure in exploring new potential gas fields. This will eventually force the consumers to opt for LPG cylinders for cooking which is financially burdensome for most people especially for people belonging to lower economic backgrounds. The monthly expense for LPG consumption by a typical Bangladeshi family is approximately BDT 940 [26]. Moreover, gas cylinders pose a higher risk of fire accidents and health hazards which can introduce catastrophic consequences to the people living in semi-enclosed, un-ventilated, concrete environments in urban areas [27-30].

It is evident that in contrast with TCS and ICS, both of which use biomass, gas stoves are far more convenient. In addition to the type of cooking fuel, place of cooking and category of cook stoves plays a pivotal role in dictating the severity of health hazard and other casualties. As claimed by the Bangladesh Demographic and Health Survey (BDHS) report 2014, $68 \%$ of the total population in Bangladesh cooks in a separate shed outside their main house, whereas the percentage of people cooking in the main house is $15 \%$ and 
the percentage of people cooking outside under open sky is $17 \%$ [31]. In fact, the kitchen structure in rural areas is not that sound which makes it awfully challenging to keep the cook stoves and biomass dry. Considering all these drawbacks of traditional cooking systems, it is undoubtedly an important issue to look for an alternative cooking fuel that is environment friendly, not detrimental to human health, comparatively inexpensive, and can cater as a sustainable solution for the next generation. A number of studies have been conducted in different countries to evaluate the transition from solid fuels to cleaner fuels such as ICS, biogas, and NG/LPG [32-35].

Taking into account the current surplus power generation capacity, and higher efficiencies of electric cooking devices, electric cooking appears to be a promising solution. Many studies based on experimental results have also shown that electric cooking consumes less energy compared to other cooking fuels [36-38]. However, it is necessary to understand the benefits and limitations of adopting electric cooking from the studies done on this topic. Only a few studies have been conducted focusing on the transition to electric cooking. Gautam et al. [39] conducted a study involving Nepalese households that revealed that participants were able to cook almost $83 \%$ of their meals using electric cooking appliances. Another study focusing on the penetrations of electric pressure cookers (EPCs) in a Tanzanian mini-grid showed that the monthly energy consumption escalated by $20 \%$ due to cooking with EPCs [40]. Kweka et al., in another study, showed that the use of EPC reduced the cooking time by $12 \%$ and the charcoal use by $45 \%$ [41]. Electric cooking diary studies were first initiated by Modern Energy Cooking Services (MECS) in four countries: Tanzania, Kenya, Zambia, and Myanmar [42-45]. This six-week-long study shows that appliances are highly compatible to cook local dishes and almost $90 \%$ of the cooking could be done. Another study by Leary et al. [46] highlighted the challenges and opportunities of electric cooking from a consumer behavior perspective. Some of the studies focused on using both electricity and solar energy to reduce the cost and to lighten the burden on the power network [47-49].

Even with these immense benefits, electric cooking is not at all a prominent cooking fuel and has not gained popularity in Bangladesh (less than 1\% [1]). Such a minute trend is set by a variety of factors including a mass perception that electric cooking is relatively pricey than biomass or gas, an unreliable power supply, cooking appliances are costly and of sub-standard quality, and lack of awareness about the health benefits of electric cooking. There is also a fear that the wide spread use of electric cooking appliances might overload our power distribution network. Therefore, it is particularly important to conduct a study to obtain preliminary electric cooking energy data in rural Bangladesh. It is also important to identify the factors that may hinder the adoption of electric cooking in Bangladesh. Moreover, to make electric cooking attractive to common people, the monthly cost of electricity consumed by cooking appliances plays a critical role. The existing studies do not focus on estimating the monthly expense of electric cooking. It is obvious that most people would only be inclined to electric cooking if it is proven to be a cost-effective alternative to their usual expenses for traditional cooking fuels. In this context, this study presents an estimate of the monthly energy consumption and associated energy bill if electric cooking appliances completely replace traditional fuels such as biomass and gas.

In this study, we collected data from three real users from a typical rural area to estimate the amount of electric energy consumed by different cooking appliances-rice cooker (RC), hot plate (HP), induction cooker (IndC), and electric pressure cooker (EPC) - required for cooking common Bangladeshi food items. We also tried to identify which appliance is the most suitable for which food item and what are the shortcomings of the appliances as far as cooking of Bangladeshi foods are concerned. After the completion of the study, feedback was taken from the end-users to understand whether their pre-occupied perception of electric cooking had changed or not. A financial analysis was conducted to make a rough estimate of the monthly expenses associated with electric cooking in comparison to the cost of traditional biomass and gas-based cooking. 


\section{Methodology}

This study was conducted to obtain a primary impression on energy requirements and expenses associated with electric cooking for making it a viable clean energy option for cooking in Bangladesh. The following major tasks were performed to satisfy the needs of the study:

- $\quad$ A limited market survey was conducted to select a wide range of electric cooking appliances considering the availability, awareness, accessibility, affordability, adroitness, and acceptance of the appliances among mass people. After the market survey, four kinds of appliances were selected to carry out the study: Rice cooker (RC), hot plate (HP), induction cooker (IndC), and electric pressure cooker (EPC). HP and IndC are general-purpose cooking appliances, mainly electric burners that require separate cook pots and can be used to cook any type of food item, whereas RC and EPC are specially designed cook pots that cook food in a concealed environment.

- Three families from different social and economic statuses were selected in a rural area in Nilphamari district to maintain a cooking diary for about four months. A local technical staff member was employed to oversee the study.

- Data were analyzed to estimate the approximate monthly energy consumption and the associated cost a family consisting of 5-6 members can expect if they adopt electric cooking.

- $\quad$ Feedback was taken from the consumers to mark the challenges, if minimized, will pave the way for popularizing electric cooking in Bangladesh.

\section{Electric Cooking Diary: Field Test Data}

\subsection{Selection of Site}

For the study purpose, we selected Jaldhaka, a sub-district of Nilphamari district in Rangpur division, located in the northern part of the country, approximately $300 \mathrm{~km}$ away from the capital city Dhaka as our site. Most families at Jaldhaka use TCS for their everyday cooking. However, a few families use LPG cylinders as backup. Our survey revealed that as an outcome of rapid grid extension, electric rice cookers are also becoming popular with few families who belong to a solvent class of that area. However, these families are not at all familiar with other categories of electric cooking appliances.

\subsection{Selection of Users}

Due to the staggering COVID-19 outbreak across the country, it was not possible to conduct any large-scale survey and hence we collaborated with a local polytechnic institute to supervise the selection of the respondents. Three households were chosen who belong to different income classes of that society and some basic information was obtained from them. However, for the sake of anonymity, we have omitted their real names and used their alias. Table 1 presents the basic information regarding the financial, educational background, and the cooking practices of the respondents. This is to mention that Raisa and Faria belong to the same household and both are engaged in cooking.

All three families reported about the drawbacks of their traditional cooking practices. All the families have their kitchen outside their main building and use a separate shed or the kitchen area to store firewood. Figure 1 depicts the typical outdoor kitchen and firewood storage shed at Jaldhaka. Jaldhaka experiences torrential rain during the monsoon especially from June to October. All three respondents raised the following common difficulties with their prevailing kitchen environment and cooking practices:

- Heavy rainfall sweeps away their kitchen area; three-stone cook stove and firewood stored outside. As a result, they cannot use the kitchen to prepare meals during heavy downpours. Only Raisa has an LPG burner. Anisa and Sheuli have to depend on dry foods such as puffed or flattened rice, bread, banana, etc. in such adverse weather conditions.

- Even if there is no rain, it is extremely difficult to ignite the firewood due to its high moisture content. 
- When firewood is burnt in the kitchen, a heavy pall of dense smoke and fumes is created. Women and children, who spend a significant amount of time in the kitchen are subjected to respiratory and eyesight issues. Sheuli reported that she usually needs to take an inhaler as her asthma gets worse when she frequently uses the kitchen.

- The deposition of carbon soot in the ceiling of the kitchen and blackening of kitchen utensils poses a high threat to kitchen hygiene. Sometimes soot gets mixed with cooked food also.

- During rainy days and nighttime it becomes inconvenient to use the outside kitchen especially for female members of the family.

Table 1. Basic information about the households chosen for study.

\begin{tabular}{|c|c|c|c|}
\hline Name & Raisa and Faria & Anisa & Sheuli \\
\hline Address & Madrashapara & Koranipara & Kamarpara \\
\hline Gender & Female & Female & Female \\
\hline Education & $\begin{array}{l}\text { Raisa: Class } 8 \\
\text { Faria: Masters }\end{array}$ & Class 9 & Class 8 \\
\hline Family members & 6 & 6 & 5 \\
\hline Total monthly Income, BDT & 30,000 & 20,000 & 12,000 \\
\hline Total monthly electricity bill, BDT & 600 & 500 & 500 \\
\hline Location of the kitchen & Outside main building & Outside main building & Outside main building \\
\hline Primary cooking fuel & Biomass & Biomass & Biomass \\
\hline Secondary cooking fuel & $\mathrm{N} / \mathrm{A}$ & LPG & $\mathrm{N} / \mathrm{A}$ \\
\hline No of burners used & 1 & 1 & 1 \\
\hline Experience on electric cooking appliance & Yes & Yes & Yes \\
\hline Electric cooking appliance used & Rice cooker & Rice cooker & Rice cooker \\
\hline $\begin{array}{l}\text { Approximate monthly fuel cost for } \\
\text { cooking, BDT }\end{array}$ & 800 & 800 & 650 \\
\hline Daily hour spent in kitchen & 3 & 3 & 2 \\
\hline $\begin{array}{l}\text { Approximate monthly expense for } \\
\text { medicine related to kitchen pollution, } \\
\text { BDT }\end{array}$ & 400 & 400 & 1200 \\
\hline
\end{tabular}

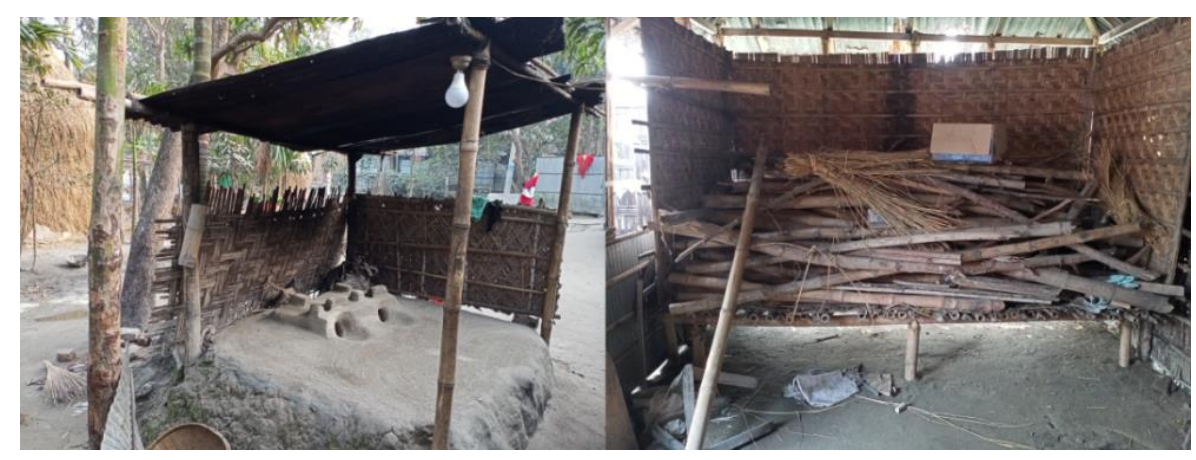

Figure 1. A typical outdoor kitchen (left) and firewood storage shed (right) at Jaldhaka, Nilphamari.

\subsection{Collection and Analysis of Cooking Data}

Due to the COVID-19 outbreak, it was not possible to visit the site by us and therefore a technical staff working for Jaldhaka Polytechnic Institute was employed to oversee the entire process. First of all, a safe electrical connection was established to operate the cooking appliances. Then, a separate energy meter was installed to measure the energy consumed by electrical cooking appliances while cooking meals. Selected households were provided with four electric cooking appliances, one at a time, a weighing scale for measuring the amount of ingredients used in cooking, and a compatible cooking pan. Most of the rural areas experience frequent power cuts and since during power cuts it is not possible to use 
the electric cooking appliances, we requested the participants of the study to keep a note of what percentage of the total cooking could be carried out with electrical appliances.

All households were supplied with the rice cooker (RC), hot plate (HP), induction cooker (IndC), and electric pressure cooker (EPC) and were requested to use only one device at a time for at least 15 days, make the most of cooking and measure the amount of food cooked, the time required in the cooking process, and most of all energy meter reading. We arranged several training sessions and online meetings to impart the necessary knowledge and skills required for operating appliances and keeping data. Respondents were briefed about the importance of maintaining the authenticity of the data-keeping process. Moreover, the appointed staff frequently visited the houses and monitored the cooking and data storing process. Data were collected on a weekly basis and analyzed for any irrelevancies. Figure 2 shows all the users whilst cooking foods using provided electric cooking appliances.

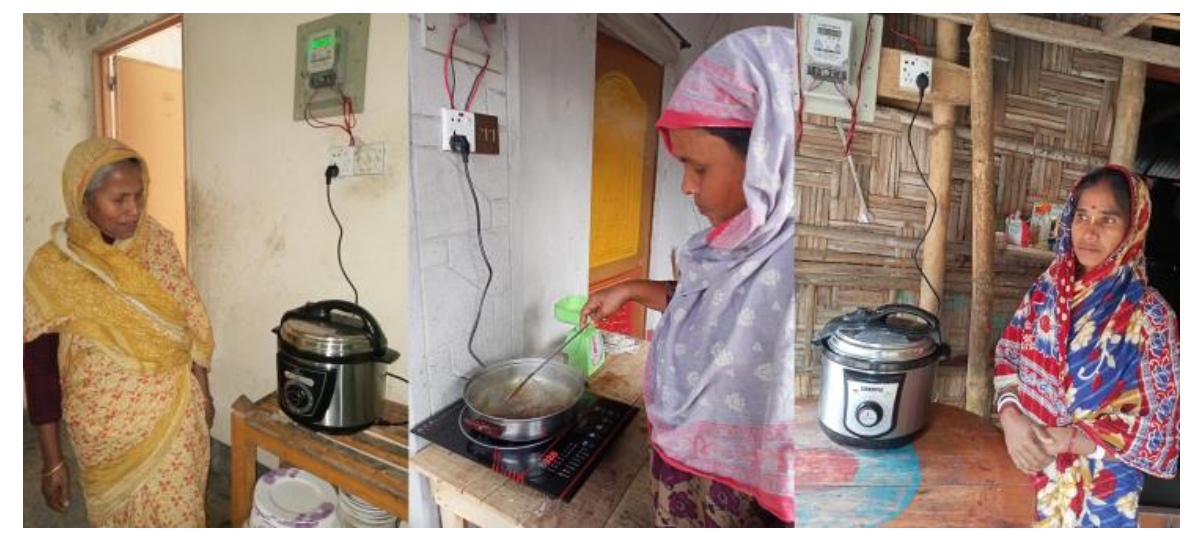

Figure 2. Respondents using electric cooking appliances (Anisa, Raisa and Sheuli from left to right).

Participants were requested to cook traditional Bangladeshi food items that the majority of the people consume on a regular basis. Priority was given on cooking main dishes such as rice, lentil soup, vegetable, fish curry, and sometimes chapati. Bangladeshi foods can be prepared in a variety of ways. While cooking curry dishes, the amount of water added and the amount of time used for boiling and making the gravy thick enough as per appetite dictates the energy required. Again, rice can be boiled in two ways: one way is to use excessive amounts of water and then filter the rice gruel after the rice is properly boiled; another way is to use water to such an extent that no gruel is left at the end of cooking rice. In addition to the cooking process, the type of rice also dictates the cooking time. The amount of water used to cook any dish and the time taken to complete the cooking varies from day to day, person to person. Therefore, it is well expected to observe variation in cooking data. However, the dominant cooking practice for each type of item is presented below:

- Rice: Boiled rice is the main dish consumed by the Bangladeshi population. After washing a few times, people typically use $2.5 \mathrm{~kg}$ of water for boiling $1 \mathrm{~kg}$ of rice and the cooking pot is placed on the stove and cooked until the rice becomes soft enough for consumption. Once the rice is cooked, the rice gruel is then filtered although the gruel can contain nutrients.

- Lentil Soup: The thickness of the lentil soup varies as per people's appetite. Usually, $1 \mathrm{~kg}$ of water, salt, and turmeric (as per taste) is mixed with $100 \mathrm{~g}$ lentil and boiled until the lentil gets completely dissolved in water and forms a thick soup-like texture. Afterwards, this soup is tempered with fried onion, garlic, and red chili.

- Vegetables: Vegetables are taken in Bangladeshi meals as starters. Two processes of cooking vegetables are followed in Bangladesh-one is sauté vegetable where the chopped vegetables are fried in the hot oil and salt, onion, and other spices are mixed as per taste, another way to is cook vegetable curry where water is mixed to give it 
a thick texture. Green vegetables such as spinach and leaves of different vegetable plants are often cooked in Bangladeshi households.

- Fish Curry: As freshwater fishes can be found in plethora in Bangladesh, it is one of the major main dishes in local households. Fish curries can either be cooked with pre-fried fish or raw fish. In the first approach, fishes are covered in spices such as salt, turmeric, and red chili powder and then fried until they turn brown. Later, gravy is prepared with onion paste, garlic paste, and other spices such as cumin paste, coriander paste, and then cooked until the gravy gets thick as per choice. In the latter approach, the same cooking process is followed but the raw fish is used. In both the process, sometimes, vegetables such as potato, tomato, cabbage, beans, pointed guards, cauliflowers, and others are added.

- Chapati: Chapati, often called roti, is made from wheat flour dough. The doughs are cut into small pieces, pressed to round shapes, and then baked on a hot pan with or without oil. This item is popular in urban areas as a breakfast item and usually consumes high energy during baking.

We sought a real scenario, therefore, no intervention was made and respondents were allowed to cook freely as they wish. After collecting the data, we could see that significant variations are present in the data while cooking the same dish on different days using the same appliance. After a thorough investigation, we found that since the respondents were using these appliances for the first time, they faced some degree of difficulty in understanding the appropriate mode of cooking. We ignored a few highly deviated data as keeping these data can imply erroneous outcomes of the study and thus tried to present the data considering the variations in food amount, the time required to complete the cooking, and energy consumption.

Table 2 reveals a wide range of variation in cooking data due to the lack of knowledge in operating electric cooking appliances. Following observations can be made based on the presented data:

- $\quad$ EPC is the most efficient appliance in terms of cooking time and energy. The respondents, while cooking with EPC, used the same amount of water as other appliances and due to lack of operating knowledge, the EPC lid was not properly sealed. While making fish curry, the respondents had pre fried the fish in the EPC keeping the lid open before going into the main stage of cooking.

- Despite its lower cost compared to other appliances, HP was not a popular choice due to the premature activation of the thermostat and failure of insulation leading to mild electric shock.

- None of the respondents could cook lentil soup with IndC. The IndC was not provided with any special cook pot suitable for cooking lentil soup. Only one small cook pot was provided with the induction cooker and the respondents preferred to cook main dishes such as rice and curry items with that. Therefore, in many cases, they cooked other food items in their alternative cooking appliances. We realized at a later stage that the size of the pan was not big enough to cook lentil soup on it and the users altogether avoided cooking lentil soup in induction cookers. Therefore, Table 2 does not contain any data associated with lentil soup while cooking with IndC.

The respondents reported about their inability to cook certain food items with the provided appliances and also mentioned that they could not perform $100 \%$ of their cooking due to power cuts and lack of knowledge or appropriate cook pot. Therefore, we asked them to keep a note on what percentage of cooking they could do with any given appliance. Data were collected for each appliance regarding the days of use, total energy consumption, and percentage of cooking done by any cooking appliance. The energy consumption data for a certain cooking percentage was scaled to $100 \%$ to estimate the energy requirement per day. 
Table 2. Cooking data for different appliances.

\begin{tabular}{|c|c|c|c|c|}
\hline Appliance & Item & $\begin{array}{c}\text { Amount, } g \\
\text { (With Water and Others *) }\end{array}$ & Time, min & Energy, kWh \\
\hline \multirow{4}{*}{ Hot plate (HP) } & Rice & $1200-2000$ & $50-60$ & $0.48-0.65$ \\
\hline & Lentil soup & $600-2200$ & $30-50$ & $0.50-0.70$ \\
\hline & Vegetable & $1000-1300$ & $40-50$ & $0.50-0.85$ \\
\hline & Fish & 1500-1800 & $30-48$ & $0.45-0.90$ \\
\hline \multirow{4}{*}{ Rice cooker (RC) } & Rice & $1000-1800$ & $40-60$ & $0.32-1.01$ \\
\hline & Lentil soup & $800-1300$ & $30-65$ & $0.40-0.96$ \\
\hline & Vegetable & $600-1200$ & $45-55$ & $0.63-0.85$ \\
\hline & Fish & $800-1500$ & $32-70$ & $0.67-0.90$ \\
\hline \multirow{4}{*}{ Induction cooker (IndC) } & Rice & $1400-2000$ & $30-60$ & $0.60-0.9$ \\
\hline & Lentil soup & $\mathrm{N} / \mathrm{A}$ & $\mathrm{N} / \mathrm{A}$ & $\mathrm{N} / \mathrm{A}$ \\
\hline & Vegetable & $1200-1400$ & $40-60$ & $0.90-1.05$ \\
\hline & Fish & 1000-1500 & $60-70$ & $0.74-0.90$ \\
\hline \multirow{4}{*}{ Electric pressure cooker (EPC) } & Rice & 1000-2000 & $34-42$ & $0.35-0.43$ \\
\hline & Lentil soup & 700-1000 & $45-60$ & $0.25-0.48$ \\
\hline & Vegetable & $1200-2200$ & $30-49$ & $0.38-0.89$ \\
\hline & Fish & $1000-1300$ & $25-30$ & $0.3-0.35$ \\
\hline
\end{tabular}

* Others in the table refer to the combined amount of oil, onion, salt, potato, and spices added while cooking.

The cumulative data presented in Table 3 also refer to some level of inconsistency. Some of the major findings are explained below:

- The high energy consumption of the RC and especially EPC is due to the fact that in many cases, the lid was kept open while cooking. As a result, the steam escaped with some heat energy that could otherwise reduce the cooking time and hence energy.

- Table 3 also shows that all three families have a similar energy consumption pattern as the number of family members is also the same.

- The expected monthly consumption varies from 80 to $85 \mathrm{kWh}$. This value seems quite high for a family of 5-6 members. However, by mastering proper operating skills and appropriate cooking methods, this can be reduced by a significant margin.

Table 3. Complied energy consumption data.

\begin{tabular}{|c|c|c|c|c|c|c|c|}
\hline Name & Category & $\begin{array}{l}\text { Rice Cooker } \\
\text { (RC) }\end{array}$ & $\begin{array}{l}\text { Hot Plate } \\
\text { (HP) }\end{array}$ & $\begin{array}{c}\text { Induction } \\
\text { Cooker (IndC) }\end{array}$ & $\begin{array}{l}\text { Electric Pressure } \\
\text { Cooker (EPC) }\end{array}$ & Total & $\begin{array}{c}\text { Energy/Month, } \\
\text { kWh }\end{array}$ \\
\hline \multirow{4}{*}{ Raisa } & Days & 43 & 31 & 24 & 15 & 113 & \multirow{4}{*}{85.8} \\
\hline & Energy, kWh & 119 & 75.2 & 47.3 & 33.1 & 274.8 & \\
\hline & $\%$ of cooking & 90 & 90 & 70 & 80 & $\mathrm{~N} / \mathrm{A}$ & \\
\hline & Energy/day, kWh & 3 & 2.7 & 2.8 & 2.8 & 2.9 & \\
\hline \multirow{4}{*}{ Anisa } & Days & 44 & 30 & 24 & 14 & 112 & \multirow{4}{*}{84.6} \\
\hline & Energy, kWh & 86.2 & 97.8 & 33.7 & 29.8 & 247.6 & \\
\hline & $\%$ of cooking & 80 & 90 & 60 & 70 & $\mathrm{~N} / \mathrm{A}$ & \\
\hline & Energy/day, kWh & 2.5 & 3.6 & 2.3 & 3 & 2.8 & \\
\hline \multirow{4}{*}{ Sheuli } & Days & 30 & 41 & 23 & 25 & 119 & \multirow{4}{*}{81.6} \\
\hline & Energy, kWh & 58.3 & 113 & 42.5 & 64 & 277.5 & \\
\hline & $\%$ of cooking & 90 & 90 & 65 & 80 & $\mathrm{~N} / \mathrm{A}$ & \\
\hline & Energy/day, kWh & 2.16 & 3 & 2.8 & 2.8 & 2.7 & \\
\hline
\end{tabular}

\subsection{User Feedback}

Before adopting full-scale electric cooking, all the respondents had limited experience of using electric cooking appliances. All of the respondents were dissatisfied with their traditional biomass-based cooking in terms of kitchen hygiene, access to an outdoor kitchen during monsoon, amount of time to be invested in cooking, and also their expenditure on 
purchasing firewood. After completion of the study period (almost 120 days), respondents were interviewed independently to understand their real-life experience. The following feedbacks were significant:

- Hot plate, due to its troublesome performance, was the least preferred appliance. Upon investigation, it was found that the thermostat malfunctioned and was causing electric shock due to leakage of electrical connection.

- With prior experience of using a rice cooker, all the respondents agreed that a rice cooker is very suitable for cooking rice as rice is cooked automatically. However, they commented that the rice cooker was taking longer while cooking other food items.

- Induction cooker was highly appreciated by all the participants as the top glass surface does not get heated. Aluminum saucepans are dominant in Bangladeshi households which are not compatible with induction cookers. Only one compatible iron pan was provided with the induction and the size of the pan was not big enough to cook lentil soup on it, therefore, they could not cook almost $30 \%$ of their foods.

- Electric pressure cooker was unanimously the most preferred appliance of all. Endusers were highly satisfied with the fact that EPC can be used to cook the majority type of food in the shortest possible time with no continuous monitoring required.

\section{Financial Analysis: Cost of Electric Cooking}

Despite some regional and seasonal variation, a typical Bangladeshi lunch or dinner comprises rice, a vegetable, a lentil soup/dal, and a fish or meat curry. Fish is the most popular choice due to availability and expense. Usually, people in Bangladesh consume meat once a week due to the high price of meat, especially beef and mutton. Chapati, a kind of flatbread, although is popular in urban areas, more than $50 \%$ of the rural people still take rice for their breakfast. We first tried to estimate the amount of food that a Bangladeshi family, consisting of 5-6 members, is likely to consume every day and then asked our respondents to cook the same amount of food several times with the provided appliances. To validate the energy consumption data derived from the participants, we decided to cook the same dishes in our laboratory using the same appliances. Although utmost scientific practices were adopted in the laboratory, the usual cooking practices were followed to keep conformity with the traditional cooking. Our lab test data demonstrates how much energy consumption can be reduced if sufficient expertise on handling these appliances develops over time. Although there is still scope for further improvement in the cooking energy consumption figure, we did not try it in the lab as it may be considered as a major change in habit. Later, data from the lab and field were analyzed to assess the cost of electrical cooking.

The presented data in Table 4 shows that for a typical family consisting of 5-6 members and three meals a day, the average daily energy consumption is $2.9 \mathrm{kWh}$ from field level and $2.5 \mathrm{kWh}$ from the lab. The table shows that the actual energy consumption from all the cooking of the food items consumed less energy in the lab environment except for chapati. It indicates that proper training on the cooking appliances can save significant energy. In the case of chapati, as the level of baking varies with the taste of the families, the chapati baked in the lab might have been slightly over-baked. However, adopting EPC can reduce energy consumption by up to $25 \%$. Even if we ignore EPC for its high cost, average monthly energy consumption will vary within 75 to $87 \mathrm{kWh}$. The electricity tariff in Bangladesh is given in Table 5 [50].

A demand charge and $15 \%$ VAT on current dues are to be separately added to calculate the actual energy bill. The demand charge is BDT $30 / \mathrm{kW}$ of sanctioned load. Since only one energy meter is connected to each family, the amount of energy $(\mathrm{kWh})$ for cooking will be added to the household energy consumption for other domestic loads. On the higher side, we considered the average cost of energy to be BDT $7.00 / \mathrm{kWh}$. For this tariff, the cost of monthly electric cooking will vary from BDT 504 to 609 . This cost can be minimized by adopting energy-efficient cooking appliances such as EPC and a slower cooking mode. 
Table 4. Comparison of lab test and field test data for cooking a typical daily meal.

\begin{tabular}{cccc}
\hline Food Item & Amount & Energy (Field), kWh & Energy (Lab), kWh \\
\hline Rice & $2500 \mathrm{~g}$ & 0.5 & 0.45 \\
Lentil soup & $800 \mathrm{~g}$ & 0.55 & 0.5 \\
Vegetable & $1000 \mathrm{~g}$ & 0.7 & 0.55 \\
Fish & $1200 \mathrm{~g}$ & 0.8 & 0.6 \\
Chapati & $10 \mathrm{pcs}$ & 0.35 & 0.4 \\
\hline
\end{tabular}

Table 5. Electricity tariff in Bangladesh.

\begin{tabular}{cccccccc}
\hline Units, kWh & $0-50$ & $0-75$ & $76-200$ & $201-300$ & $301-400$ & $401-600$ & $>600$ \\
\hline Tariff, BDT & 3.75 & 4.19 & 5.72 & 6.00 & 6.34 & 9.94 & 11.46 \\
\hline
\end{tabular}

The average expenditure of the participating households for purchasing their monthly firewood was BDT 800. To compare the cost of electric cooking with traditional biomassbased cooking and LPG burner, we cooked the same amount of food as presented in Table 4 using an LPG burner in our lab. In Bangladesh, the price of a $12 \mathrm{~kg}$ LPG cylinder is around BDT 1000 (BDT 0.083/g or BDT 4.96/kWh). Table 6 presents the cooking data for cooking daily foods required for a family consisting of 5-6 members using an LPG burner.

Table 6. Cooking energy data from LPG burner.

\begin{tabular}{cccccc}
\hline Category & Rice & Lentil Soup & Vegetable & Fish & Chapati \\
\hline $\begin{array}{c}\text { Amount of food, } \mathrm{g} \\
\text { (including water) }\end{array}$ & 2500 & 800 & 1000 & 1200 & 500 \\
\hline LPG consumed, $\mathrm{g}$ & 65 & 85 & 40 & 90 & 35 \\
\hline
\end{tabular}

From Table 6, we can see that the daily consumption of LPG for preparing three meals for a family of 5-6 members is $315 \mathrm{~g}$. Therefore, monthly consumption will be $9.45 \mathrm{~kg}$ resulting in a monthly expense of BDT 784. However, the actual LPG consumption under a different cooking condition can vary by $10-15 \%$. The cost of different cooking fuels required for a family of 5-6 members is presented in Table 7 .

Table 7. Comparative cost of cooking using different fuels.

\begin{tabular}{cccc}
\hline Category & Firewood & LPG & Electricity \\
\hline $\begin{array}{c}\text { Monthly cooking energy cost } \\
\text { for a family of 6 members, BDT }\end{array}$ & 800 & 784 & 552 \\
\hline $\begin{array}{c}\text { Monthly cooking energy cost } \\
\text { for a family of 6 members, USD }\end{array}$ & 9.41 & 9.22 & 6.49 \\
\hline
\end{tabular}

From Table 7, it is evident that electric cooking is less expensive compared to biomass and LPG. However, adopting electric cooking requires an initial investment for purchasing the appliances, and the price of appliances can differ by a large margin from each other. Electric pressure cooker, although most efficient, costs slightly higher (USD 70-112) that might not be affordable for lower-income families. An induction cooker (USD 39-62) which is less expensive than EPC can be a good choice for families who are financially solvent but not affluent. Curry cookers are electric cooking appliances that have higher thermostat settings than the rice cooker and all types of meals can be cooked with this as it is almost similar to a saucepan that runs on electricity. Despite the fact that curry cookers (USD 35-57) are cheaper than induction cookers, the need of transferring cooked food to another pot before cooking a new dish can make an induction cooker a better choice. However, in that case, additional costs for purchasing compatible cook pots need to be considered. 
Rice cookers are the least expensive among all, yet not very feasible for cooking other food items except for rice. Hot plates are the least recommended appliances due to their high energy consumption and poor technical quality and performance. The participating families also emphasized that if a monthly installment facility is provided they can make a partial down payment and pay the rest in installments accepting an extra expense of BDT 300-600 per month. This idea, if implemented as a business model, can significantly make electric cooking even more affordable and popular. All the respondents corroborated this business model. However, it is important to realize that the presented data, although may not be claimed to be based on a large data sample, it is indicative of the situation which can be helpful in designing a large-scale study in the future.

\section{Prospects and Challenges of Electric Cooking in Bangladesh}

In the last decade, Bangladesh has demonstrated steady growth in terms of purchasing capacity of the people. The initial investment for electric cooking appliances may be a bit higher than TCS but quite close as compared with LPG burners. The lab and field data of the cooking diary and the user's feedback opens up a lot of advantages and prospects of electric cooking in Bangladesh.

- Environment friendly: Adoption of electric cooking can significantly reduce deforestation and GHG emission provided that the penetration of renewable energy increases in the national grid as the current contribution of renewable energy-based power generation is only $0.59 \%$ (except hydro) in Bangladesh [51].

- Affordable cooking fuel: The cost of electricity as a cooking fuel is always comparable and often cheaper than other available options.

- Less troublesome: Electric cooking appliances can be used in the indoor kitchen and consume electricity to cook food. It eliminates the problem of keeping the cook stove, biomass, and kitchen area dry.

- $\quad$ Better kitchen accessibility: Electric cooking enables the consumers to cook inside their main building and avoid outdoor cooking. Raisa, one of the respondents, mentioned that she does not face any problem using the appliances during nighttime or rainy days which is troublesome outdoors especially in open sky kitchens.

- Healthy cooking: Electric cooking appliances do not produce any unhealthy fumes or smoke. No carbon soot is deposited on the ceiling and cook pots also remain comparatively clean. One of the respondents, Sheuli, mentioned that after adopting electric cooking her expense for buying respiratory medicine was reduced.

- Safety: Electric cooking is less likely to cause fire hazards as compared to firewood and gas.

- $\quad$ Time saving: Electric cooking requires no continuous monitoring and this allows the users to get involved in other household chores. Raisa, one of the respondents, mentioned that after adopting electric cooking, she can now give more time to raise her grandchild and recite the Holy Quran. Anisa mentioned that her daughter-in-law can now spend more time preparing for a job. Sheuli mentioned that she can now feed her cattle in her spare time and also sew Nakshi Kantha, a type of embroidered quilt that is a new source of income for her.

Although electric cooking has numerous advantages, wide community adoption is a challenging task. There is no doubt that economic feasibility is the main concern for such a development, but we must not ignore some other factors that may have a significant impact on adopting electric cooking. These factors are:

- Awareness and training: All the respondents of this study mentioned that they had no prior idea know about induction or electric pressure cookers. The poor marketing strategy of the suppliers is also responsible for this. The lab test data shows that a significant amount of energy consumption can be reduced if proper knowledge and skill in operating these appliances can be acquired. 
- Affordability: Because of the high initial investment, electric cooking appliances are not popular with low-income families. Micro-financing with an affordable monthly installment system can be introduced so that consumers are more attracted to these appliances.

- Quality of cooking appliances: People have a fear that the investment in purchasing cooking appliances may go in vain if the quality of the appliance is not up to the mark. If the appliances frequently malfunction such as the occurrence of premature activation of thermostats, electric shock, or performance of the appliances gradually deteriorates over time, consumers will lose their trust in these appliances. Such negative experiences can act as a deterrent against the inclination towards the adoption of electric cooking.

- Technical support for maintenance of appliances: Cooking appliances, if they cannot be serviced properly once malfunctioned, can create a negative impression. Therefore, it is important to train technicians who can provide immediate support.

- Appropriate policy formulation and robust power network: There is a real possibility that if a significant share of the people adopts electric cooking, it will overburden the existing power generation and distribution system. Therefore, proper policies should be formulated and distribution infrastructure should be strengthened to promote electric cooking.

- Integration with rooftop solar: Bangladesh is blessed with an ample amount of sunlight and most of the cooking is carried out during the daytime. Therefore, the integration of solar PV in electric cooking can significantly reduce the cost of cooking.

- Reliability of power supply: Although Bangladesh has more power generation capacity than its current demand, an uninterrupted and reliable power supply is the most challenging issue for the power distribution companies due to their old and unreliable distribution system. Sudden power cuts, even for 30 min during cooking, makes it difficult for the user to complete preparing their food items, and the users lose their confidence in electric cooking.

\section{Discussion}

In a country like Bangladesh, where women spend a long span of time in the kitchen and jeopardize their health and quality of living at the expense of relatively expensive cooking fuels such as biomass and gas, the use of electricity for cooking can be a promising solution and win the confidence of the consumers by ensuring the quality, cost, and expertise of cooking appliances. This study shows that electric cooking can reduce the expense of cooking fuel, improve kitchen and food hygiene, and most importantly ameliorate the standard of living. However, the desired level of attainment will only be possible if government agencies promote electric cooking as a reflection of its conformation to make a transition towards clean and efficient cooking technologies. Since Bangladesh is a country with limited knowledge and wrong perception about electric cooking appliances, formal training needs to be launched so that wide community adoption of electric cooking can be made possible. Appliance manufacturers need to focus on the technical standard of the appliances to ensure a sustainable market. Furthermore, there should be a government policy of having technical standards of electrical cooking appliances that should be approved and monitored by a regulatory body. A further study employing a higher number of households from diverse social and economic backgrounds would definitely help to obtain a better understanding of the benefits and challenges of electric cooking, however, this study would be helpful for consumers, policymakers, appliance manufacturers, and researchers in this field who want to conduct further studies on electric cooking as a part of the transition to clean cooking technologies.

Author Contributions: All the authors equally contributed to this work. All authors have read and agreed to the published version of the manuscript. 
Funding: The project was funded by Modern Energy Cooking Services (MECS), UK, P.O. number: 500239177. The APC was funded by United International University and Independent University Bangladesh.

Acknowledgments: Authors of this article would like to acknowledge the help and support from the Research Associates: Jahirul Islam and Jahid Akter and Research Assistants: Abdullah Al Mojib and Masum Rana. The authors are also grateful to the UIU and IUB authority for extending full support for the project. Above all, the authors are grateful to MECS for their financial support of the project.

Conflicts of Interest: The authors declare no conflict of interest.

\section{References}

1. World Bank. Available online: https://data.worldbank.org/indicator/NY.GDP.PCAP.CD?locations=BD (accessed on 20 July 2021).

2. Report on Sample Vital Statistics (SVRS) 2018, Bangladesh Bureau of Statistics. Available online: https://bbs.portal.gov.bd/ sites/default/files/files/bbs.portal.gov.bd/page/6a40a397_6ef7_48a3_80b3_78b8d1223e3f/SVRS_Report_2018_29-05-2019\% 28Final\%29.pdf (accessed on 20 July 2021).

3. Power Cell. Available online: http://www.powercell.gov.bd/site/view/powerdiv_achievement_at_glance/ (accessed on 20 July 2021).

4. The Financial Express. Available online: https://thefinancialexpress.com.bd/views/power-overcapacity-in-bangladesh-161115 4075 (accessed on 20 July 2021).

5. Budya, H.; Yasir Arofat, M. Providing Cleaner Energy Access in Indonesia through the Megaproject of Kerosene Conversion to LPG. Energy Policy 2011, 39, 7575-7586. [CrossRef]

6. Cincinelli, A.; Martellini, T. Indoor Air Quality and Health. Int. J. Environ. Res. Public Health 2017, 14, 1286. [CrossRef]

7. Jetter, J.J.; Kariher, P. Solid-Fuel Household Cook Stoves: Characterization of Performance and Emissions. Biomass Bioenergy 2009, 33, 294-305. [CrossRef]

8. Anenberg, S.C.; Balakrishnan, K.; Jetter, J.; Masera, O.; Mehta, S.; Moss, J.; Ramanathan, V. Cleaner Cooking Solutions to Achieve Health, Climate, and Economic Cobenefits. Environ. Sci. Technol. 2013, 47, 3944-3952. [CrossRef]

9. Zhang, J.; Smith, K.R. Household Air Pollution from Coal and Biomass Fuels in China: Measurements, Health Impacts, and Interventions. Environ. Health Perspect. 2007, 115, 848-855. [CrossRef] [PubMed]

10. de Oliveira Galvão, M.F.; de Oliveira Alves, N.; Ferreira, P.A.; Caumo, S.; de Castro Vasconcellos, P.; Artaxo, P.; de Souza Hacon, S.; Roubicek, D.A.; Batistuzzo de Medeiros, S.R. Biomass Burning Particles in the Brazilian Amazon Region: Mutagenic Effects of Nitro and Oxy-PAHs and Assessment of Health Risks. Environ. Pollut. 2018, 233, 960-970. [CrossRef]

11. Sigsgaard, T.; Forsberg, B.; Annesi-Maesano, I.; Blomberg, A.; Bølling, A.; Boman, C.; Bønløkke, J.; Brauer, M.; Bruce, N.; Héroux, M.-E.; et al. Health Impacts of Anthropogenic Biomass Burning in the Developed World. Eur. Respir. J. 2015, 46, 1577-1588. [CrossRef]

12. Bates, M.N.; Chandyo, R.K.; Valentiner-Branth, P.; Pokhrel, A.K.; Mathisen, M.; Basnet, S.; Shrestha, P.S.; Strand, T.A.; Smith, K.R. Acute Lower Respiratory Infection in Childhood and Household Fuel Use in Bhaktapur, Nepal. Environ. Health Perspect. 2013, 121, 637-642. [CrossRef]

13. Bonan, J.; Pareglio, S.; Tavoni, M. Access to Modern Energy: A Review of Barriers, Drivers and Impacts. Environ. Dev. Econ. 2017, 22, 491-516. [CrossRef]

14. Clean Cooking Alliance. Available online: https://www.cleancookingalliance.org/country-profiles/focus-countries/6bangladesh.html (accessed on 22 July 2021).

15. WHO Guidelines for Indoor Air Quality: Household Fuel Combustion. Available online: https://www.who.int/publications/i/ item/9789241548885 (accessed on 23 July 2021).

16. Hazra, S. Adoption and Use of Improved Stoves and Biogas Plants in Rural India. In SANDEE Working Papers; South Asian Network for Development and Environmental Economics: Kathmandu, Nepal, 2014; Available online: http: / / www.sandeeonline. org/uploads / documents / publication/1037_PUB_Working_Paper_86_Somnath.pdf (accessed on 27 July 2021).

17. Shrimali, G.; Slaski, X.; Thurber, M.C.; Zerriffi, H. Improved Stoves in India: A Study of Sustainable Business Models. Energy Policy 2011, 39, 7543-7556. [CrossRef]

18. Asik, U.S.; Masakazu, T. Fuelwood Consumption and Its Impact on Forests in the Teknaf Peninsula on the Southern Coast of Bangladesh. Am. J. Environ. Sci. 2017, 13, 225-232. [CrossRef]

19. Miah, M.D.; Al Rashid, H.; Shin, M.Y. Wood Fuel Use in the Traditional Cooking Stoves in the Rural Floodplain Areas of Bangladesh: A Socio-Environmental Perspective. Biomass Bioenergy 2009, 33, 70-78. [CrossRef]

20. Shawkat, M.; Sohel, M.S.; Parvez, M.; Akhter, S.; Rana, P. Linking Biomass Fuel Consumption and Improve Cooking Stove: A Study from Bangladesh. In Proceedings of the 21st World Energy Conference, Montreal, QC, Canada, 11-16 September 2010; Available online: https:/ / www.osti.gov/etdeweb/servlets/purl/21390212 (accessed on 23 July 2021).

21. Bangladesh Country Action Plan for Clean Cookstoves. Available online: http://www.sreda.gov.bd/d3pbs_uploads/files/ policy_5_cap_final.pdf (accessed on 25 July 2021). 
22. Islam, M.S.; Khanam, M.; Rouf, M.A.; Rahaman, M. Performance Evaluation of Improved Cook Stoves (ICS) Disseminating in Bangladesh. Bangladesh J. Sci. Ind. Res. 2014, 49, 219-226. [CrossRef]

23. Jan, I.; Ullah, S.; Akram, W.; Khan, N.P.; Asim, S.M.; Mahmood, Z.; Ahmad, M.N.; Ahmad, S.S. Adoption of Improved Cookstoves in Pakistan: A Logit Analysis. Biomass Bioenergy 2017, 103, 55-62. [CrossRef]

24. Khandelwal, M.; Hill, M.E.; Greenough, P.; Anthony, J.; Quill, M.; Linderman, M.; Udaykumar, H.S. Why Have Improved Cook-Stove Initiatives in India Failed? World Dev. 2017, 92, 13-27. [CrossRef]

25. Ruiz-Mercado, I.; Masera, O.; Zamora, H.; Smith, K.R. Adoption and Sustained Use of Improved Cookstoves. Energy Policy 2011, 39, 7557-7566. [CrossRef]

26. Larsen, B. Benefits and Costs of Household Cooking Options for Air Pollution Control. Copenhagen Consensus Center. 2016. Available online: https:/ / www.copenhagenconsensus.com/sites/default/files/larsen_indoorairpollution.pdf (accessed on 27 July 2021).

27. Rosenthal, J.; Quinn, A.; Grieshop, A.P.; Pillarisetti, A.; Glass, R.I. Clean Cooking and the SDGs: Integrated Analytical Approaches to Guide Energy Interventions for Health and Environment Goals. Energy Sustain. Dev. 2018, 42, 152-159. [CrossRef]

28. Effects of Residential Gas Appliances on Indoor and Outdoor Air Quality and Public Health in California. Available online: https:/ / ucla.app.box.com/s / xyzt8jc1ixnetiv0269qe704wu0ihif7 (accessed on 25 July 2021).

29. Nicole, W. Cooking Up Indoor Air Pollution: Emissions from Natural Gas Stoves. Environ. Health Perspect. 2014,122, A27. [CrossRef]

30. Gas Stoves: Health and Air Quality Impacts and Solutions-RMI. Available online: https://rmi.org/insight/gas-stoves-pollutionhealth (accessed on 27 July 2021).

31. Bangladesh Demographic and Health Survey Report. 2014. Available online: https://dhsprogram.com/pubs/pdf/FR311/FR311 .pdf (accessed on 27 July 2021).

32. Lewis, J.J.; Pattanayak, S.K. Who Adopts Improved Fuels and Cookstoves? A Systematic Review. Environ. Health Perspect. 2012, 120, 637-645. [CrossRef]

33. Andadari, R.K.; Mulder, P.; Rietveld, P. Energy Poverty Reduction by Fuel Switching. Impact Evaluation of the LPG Conversion Program in Indonesia. Energy Policy 2014, 66, 436-449. [CrossRef]

34. Tembo, S.T.; Mulenga, B.P.; Sitko, N.J. Cooking Fuel Choice in Urban Zambia: Implications on Forest Cover; Michigan State University, Department of Agricultural, Food, and Resource Economics: East Lansing, MI, USA, 2015.

35. Yan, H.J. The Theoretical and Empirical Analysis on the Compatibility of Sustainable Development Strategies and Poverty Reduction Policies at Micro Level; University Aix-Marseille II: Aix-en-Provence, France, 2010.

36. Ravindranath, N.H.; Ramakrishna, J. Energy Options for Cooking in India. Energy Policy 1997, 25, 63-75. [CrossRef]

37. Cowan, B. Identification and demonstration of selected energy best practices for low income urban communities in South Africa: Implementation guidelines. In Project Deliverable No. 17 of Alleviation of Poverty through the Provision of Local Energy Services (APPLES); Project No. EIE 04-168; Intelligent Energy Europe: Luxembourg, 2008.

38. Preliminary Design and Analysis of a Proposed Solar and Battery Electric Cooking Concept: Costs and Pricing. Available online: https: / / www.gov.uk/research-for-development-outputs / preliminary-design-and-analysis-of-a-proposed-solar-andbattery-electric-cooking-concept-costs-and-pricing (accessed on 27 July 2021).

39. Gautam, B.; Pandit, S.; Clements, W.; Williamson, S.; Silwal, K. Assessing Electric Cooking Potential in Micro Hydropower Microgrids in Nepal (Project Report). 2020. Available online: https://mecs.org.uk/wp-content/uploads/2020/12/MECS-TRIIDPEEDA_updated-Report.pdf (accessed on 18 September 2021).

40. Schreiber, K.; Waceke, M.; Blair, H. Electric Pressure Cooking: Accelerating Microgrid E-Cooking through Business \& Delivery Model Innovations. 2020. Available online: https://www.clasp.ngo/research/all/electric-pressure-cooking-acceleratingmicrogrid-e-cooking-through-business-and-delivery-model-innovations / (accessed on 18 September 2021).

41. Kweka, A.; Clements, A.; Bomba, M.; Schürhoff, N.; Bundala, J.; Mgonda, E.; Nilsson, M.; Avila, E.; Scott, N. Tracking the Adoption of Electric Pressure Cookers among Mini-Grid Customers in Tanzania. Energies 2021, 14, 4574. [CrossRef]

42. Leary, J.; Scott, N.; Serenje, N.; Mwila, F.; Batchelor, S. eCook Zambia Cooking Diaries (Working Paper). 2019. Available online: https:/ / mecs.org.uk/wp-content/uploads/2020/12/eCook-Zambia-Cooking-Diaries-Report-JL-13-10-19-COMPRESSED. pdf (accessed on 17 September 2021).

43. Leary, J.; Scott, N.; Sago, S.; Minja, A.; Batchelor, B.; Chepkurui, K.; Sawe, E. eCook Tanzania Cooking Diaries (Working Paper). 2019. Available online: https:// mecs.org.uk/wp-content/uploads/2020/12/eCook-Tanzania-Cooking-Diaries-Working-Paper13-10-19-JL-COMPRESSED.pdf (accessed on 17 September 2021).

44. Leary, J.; Scott, N.; Hlaing, W.W.; Myint, A.; Sane, S.; Win, P.P.; Phyu, T.M.; Moe, E.T.; Htay, T.; Batchelor, S.; et al. eCook Myanmar Cooking Diaries (Working Paper). 2019. Available online: https://mecs.org.uk/wp-content/uploads/2020/12/eCook-MyanmarCooking-Diaries-Working-Paper-13-10-19-JL-COMPRESSED.pdf (accessed on 17 September 2021).

45. Leary, J.; Scott, N.; Numi, A.; Chepkurui, K.; Hanlin, R.; Chepkemoi, M.; Batchelor, S.; Leach, M.; Brown, E. eCook Kenya Cooking Diaries (Working Paper). 2019. Available online: https://mecs.org.uk/wp-content/uploads/2020/12/eCook-Kenya-CookingDiaries-September-2019-Working-Paper.pdf (accessed on 17 September 2021).

46. Leary, J.; Menyeh, B.; Chapungu, V.; Troncoso, K. eCooking: Challenges and Opportunities from a Consumer Behaviour Perspective. Energies 2021, 14, 4345. [CrossRef] 
47. Van Buskirk, R.; Kachione, L.; Robert, G.; Kanyerere, R.; Gilbert, C.; Majoni, J. How to Make Off-Grid Solar Electric Cooking Cheaper Than Wood-Based Cooking. Energies 2021, 14, 4293. [CrossRef]

48. Khan, M.R.; Alam, I. A Solar PV-Based Inverter-Less Grid-Integrated Cooking Solution for Low-Cost Clean Cooking. Energies 2020, 13, 5507. [CrossRef]

49. Batchelor, S.; Talukder, M.A.R.; Uddin, M.R.; Mondal, S.K.; Islam, S.; Redoy, R.K.; Hanlin, R.; Khan, M.R. Solar e-Cooking: A Proposition for Solar Home System Integrated Clean Cooking. Energies 2018, 11, 2933. [CrossRef]

50. Bangladesh Energy Regulatory Council. Available online: http://berc.org.bd/sites/default/files/files/berc.portal.gov.bd/ notices/86133373_6e68_4c88_aa49_237ba16263b4/2020-06-10-17-55-362cec32305a6e4f0bc17975a92e05e0.pdf (accessed on 27 July 2021).

51. Bangladesh Power Development Board. Available online: https://www.bpdb.gov.bd/bpdb_new/index.php/site/page/13e9-2 cc0-ce41-9c09-088d-94d5-f546-04a6-b4fa-1d18 (accessed on 19 September 2021). 